\title{
Examining local processes when applying a Cumulative Impact Policy to address harms of alcohol outlet density
}

\begin{abstract}
One approach to addressing the negative health and social harms of excessive drinking has been to attempt to limit alcohol availability in areas of high outlet density. The Licensing Act (2003) enables English local authorities the power to implement a Cumulative Impact Policy (CIP) in order to tackle alcohol challenges. More than 100 English local authorities have implemented a CIP in one or more designated areas. We examined local license decision-making in the context of implementing CIPs. Specifically, we explored the activities involved in alcohol licensing in one London local authority in order to explicate how local decision-making processes regarding alcohol outlet density occur. Institutional ethnographic research revealed that CIPs were contested on multiple grounds within the statutory licensing process of a local authority with this policy in place. CIPs are an example of multi-level governance where national and local alcohol licensing priorities, interests, and legal powers interface. Public health priorities can be advanced in the delivery of CIPs, but those priorities can at times be diluted by those of other stakeholders, both public sector and commercial.
\end{abstract}

Key Words: alcohol policy; outlet density; cumulative impact policy; alcohol licences; institutional ethnography

\section{Introduction}

The availability of alcohol is an important determinant of alcohol consumption and alcohol-related harms (Ayuka et al. 2014; Stockwell and Gruenewald 2004). A body of research now exists supporting the association between restrictions in alcohol availability and reductions in hospital admissions and the health harms of alcohol over-consumption (Babor et al. 2010; Martineau et al. 2013). This includes restrictions of economic availability (e.g., by raising the minimum unit price of alcohol (MUP); Booth et. al 2008), physical availability (e.g., by reducing the spatial density of alcohol outlets; Campbell et al. 2009), and temporal availability (e.g., by reducing hours of sales; Popova et al. 2009). Evaluations have found that interventions that seek to restrict alcohol availability can reduce health and social harms but the evidence of effectiveness varies by context, intervention, and study methods (Gmel et al. 2015).

Worldwide attention has been placed on the potential public health benefits of polices that affect the economic availability of alcohol (Babor et al. 2010). However, a lack of English Government support for MUP policies, and the legal challenges faced in the European Courts by Scottish MUP proposals, mean that local government licensing of alcohol outlets represents an important lever for modifying alcohol availability in the UK (Nicholls 2012). One approach has been to implement local government policies that aim to limit on- and/or off- premise alcohol outlet density (Campbell et al. 2009; Gruenewald and Remer 2006; Livingston et al. 2007; Martineau et al. 2013). On-premise locations may include bars, clubs, sporting facilities, and restaurants while off-premise locations include businesses such as grocery stores, convenience stores, and off licences. In some cases, 
premises hold both an on- and off- premise alcohol licence (e.g., a restaurant or bar that allows off-sales).

The Licensing Act (2003) enables English local authorities the power to implement Cumulative Impact Policies (CIPs) in order to strengthen licencing powers and limit the unwanted growth of alcohol outlet density. Under section 182 of the Act, revised guidance on cumulative impact for licensing authorities has been issued (Home Office 2015; Woodhouse 2015). Local authorities can implement a CIP by designating boundaries within their borough as cumulative impact zones (CIZs) if adverse social effects of alcohol market saturation can be demonstrated. More than 100 of 326 lower tier local authorities (LTLAs) or districts in England have implemented a CIP in one or more designated areas, resulting in at least 208 CIZs as of 2014 (Morris 2015). ${ }^{\mathrm{i}}$

The CIP intervention creates a rebuttable presumption that applications for new alcohol sales licenses or modifications of existing licences (e.g., extending opening hours) will be refused where it can be demonstrated that adding a new on or off licence will have negative social outcomes in violation of the licensing objectives (Home Office 2015; Woodhouse 2015). The four licensing objectives in England are: (1) The prevention of crime and disorder; (2) Public safety; (3) The prevention of public nuisance and (4) The protection of children from harm. It is worth noting that public health is not an explicit licensing objective in England as it is in Scotland (Scottish Executive 2007).

Martineau et al. (2013) have argued that public health interest in CIPs rests partly in in the perceived need to find deliverable means of restricting availability in the (current) absence of national-level policies such as MUP. In addition, the statutory guidance states that the case for a CIP can be supported on public health grounds, thus providing a formal route for Public Health authorities to work with and influence local licensing policy. CIPs may therefore help to address a more general dilemma that public health practitioners have a responsibility to protect the public from alcohol related harms but have limited powers to influence availability. This responsibility without authority is not confined to the UK (Martineau et al. 2013). For example Babor et al. (2010) have highlighted how the decentralisation of decision-making affecting alcohol availability has the effect of diluting or excluding the influence of public health at international, national and local levels. CIPs can therefore be considered an exemplar of how the global call for 'Health in all Policies' (World Health Organization 2010; Ollila 2011) can play out locally over the issue of alcohol availability. However, CIPs are discretionary: local authorities do not need to adopt them and those who do adopt can tailor the policy to local contexts. Hence the degree to which CIPs prioritise health relative to other alcohol related concerns both in the aims and the delivery of the policy-if health and health inequities are a concern at all-is the product of local decision-making processes.

A key gap that has been identified within the scientific literature on the social and public health consequences of alcohol outlet density is the lack of empirical research which explicates "how local decisions are made regarding policies affecting alcohol beverage outlet density or the consequences of such policy changes" (Campbell 2009: 567). In this article we use an ethnographic approach to help understand the everyday, local world of alcohol policy from the standpoint of diverse actors involved in the work of alcohol licencing in a UK London Borough. The qualitative data we present in this article explores the actualities of 
local decision-making on regulation of alcohol retail density to gain insights into how CIPs can work, who the process favours, what concerns drive the process, and where public health concerns fit within that. From this we aimed to learn more about the potential of CIPSs as a 'public health' as well as a 'licensing' intervention.

\section{Methods}

In this study we explored such decision-making processes with an approach informed by the sociological research tradition of institutional ethnography (IE). Developed by sociologist Dorothy Smith $(1987,1990,1999,2005,2006)$, IE is a research approach that allows for a consideration of complex processes of social coordination across multiple local sites such as hospitals, schools, community organizations and government agencies (Eastwood 2013; Mykhalovskiy and McCoy 2002; Rankin 2003; Smith 2006). Institutional ethnographers use qualitative data including interviews and ethnographic observation to understand issues of access and local administrative processes within and across institutions. This research tradition helps to reveal the ways in which particular institutional processes (e.g., granting a new or modified alcohol licence at the local level) are shaped by particular discourses and texts (e.g., CIPs, the Licencing Act (2003)). For example, as Campbell and Gregor (2005) explain: "texts and their activation constitute definite forms of social relations between the people involved. Mapping those relations allows analysts to identify how things are organized, how people's lives are ruled" (173).

As part of this program of research we conducted interviews with 24 participants. This included 14 semi-structured individual interviews and three small group interviews (with a total of ten participants). Research participants were purposively selected to include a diverse sample who spoke from the standpoint of their everyday work (e.g., licencing officers, councillors, police, trade) and had familiarity with local government implementation of CIPs in three English local authorities (two neighbouring authorities within London and one local authority outside of London). Potential research participants were first identified by our research partners working in local government. These participants were contacted by email to provide an explanation of the study and invite them for an interview. Additional participants were identified through a review of key policy documents, publically available licencing applications, and when attending licensing meetings in London. To protect confidentiality in what are relatively small policy areas, we have included generic job titles only, and removed all local identifying detail from quoted extracts. In addition to interviews across multiple local government areas, we conducted documentary analysis of key texts (e.g., licencing applications, representations made to the licensing committees by police, the local authority and residents etc.). All qualitative data collection took place over a ninemonth period between April-December 2014.

We observed 21 alcohol licencing meetings in 2 neighbouring London Local Authority Boroughs that had implemented CIPs. Single licencing meetings reviewed between 1 to 5 applications for alcohol sales licences and typically lasted 2-2.5 hours. These ethnographic observations are the primary data source for this analysis. In addition to formal interviews noted above, attending meetings gave opportunities for informal discussions with attendees regarding the licencing process and local concerns with alcohol availability. Licencing meetings provided us with entry into the everyday, text-mediated relations of implementing and contesting CIPs. By "text-mediated" we mean to highlight the ways in which local work practices were coordinated by statutory documents such as licencing applications and Home Office regulations. These texts served to direct sequences of action 
and inform the kinds of work carried out in the context of meetings including decisions to grant alcohol licences.

Consistent with this sociological tradition, we were concerned with examining "translocal relations of large-scale coordination" (McCoy, 2006, pp. 110-111) and ultimately exploring how alcohol policies impact the health and social lives of people at the local level. IE has had limited application in public health sciences despite obvious applicability to understanding processes of multi-level institutional regulation (Author et al. 2014). We have applied aspects of this methodological approach to this case study of CIPs to make visible not only what the intervention is intended to achieve, but what policy implementation looks like in everyday practice. This use of institutional ethnography within the realm of policy implementation builds on related transnational applications of this critical research strategy in the area of public health laws and HIV/AIDS governance (Author 2013; 2015) as well as related ethnographic research on legal decision-making process (Hawkins 2002).

This study was conducted as part of a larger programme of research examining local alcohol policies in different settings across England. Using an inductive approach, we developed local case studies areas that focused on specific alcohol interventions. In line with ethnographic research strategies, we allowed research foci and themes to emerge as fieldwork and analysis progressed. We sought to understand the experiences and concerns of people at the local level who were seeking to address the harms of alcohol outlet density. The emergent problematic that forms the basis of this paper was that the nature and purpose of cumulative impact policies appeared to be ambiguous and contested by stakeholders, both in the interventions' textual form and its application in the everyday world. We therefore developed a framework of analysis that aimed to explore the context and potential public health implications of different contested domains of this alcohol intervention.

\section{Results}

Public health actors in this Local Authority identified addressing the social and public harms related to alcohol as a priority area of local intervention, including providing local data on the health effects of alcohol consumption to help the Licencing team make the case for CIPs. In the results sections that follow, we describe how after the CIPs were created, the policy became the main mechanism for framing local alcohol licensing decisions related to outlet density. We present a simplified summative figure that outlines two complex textmediated work processes (Figure 1). The first work process highlights how a CIP is initially created, by illustrating the role of national policy guidance and local evidence (Figure 1, work process 1). The focus of our discussion here is an explication of the work process of granting an alcohol licence in the context of a CIP, outlining a process from initial application to the potential appeal of a licencing subcommittee's rejection of an application (Figure 1, work process 2). Drawing upon ethnographic data, we explore five interrelated areas where CIPs are contested in local licensing subcommittee meetings in order to account for how this alcohol outlet density policy is enacted in the context of everyday local decision-making.

\section{[Insert Figure 1 - work processes related to CIPs]}




\subsection{Licence Applications and CIPs}

To start, it is clear that applicants had varied levels of engagement with licencing officers and other responsible authorities during the process of preparing and submitting their application for a new or modified alcohol licence. While some applicants appear to have had sustained engagement with licensing officers, police, and/or local residents and businesses prior to or during the licencing application process, others submitted their applications in the absence of any such engagement. For example, one licensing officer explained her work at this stage in the licensing process:

...last week I had a meeting with a solicitor, firm of solicitors and the applicant, talking about a new application that they're going to be doing in [area of London Borough], which is a cumulative impact area. And so [I gave] pre-application advice, and some [applications for a licence] just, just turn up [...] And then we get an application, we've not heard anything about it. [Looking at folder of applications] This is another place in a cumulative impact area. I mean it's kind of good example, in one week I had people consulting with me talking about the policy, you know, how they might 'fit' into the policy, that kind of talking us through what they're envisioning how the premises is going to run, asking us what conditions we met with, I as a Licensing Officer met with them, our Noise Team and the police met with them to advise them about their application, this other one [application] just nothing (Council, licensing officer)

Here the licensing officer was contrasting the different kinds of work processes involved in licence applications that can occur prior to submission - some having lots of consultation and others simply being submitted in-person or online through a government website without advanced notice.

Licensing data collected by the local authority indicated a peak in applications in the year before the implementation of a CIP, followed by a decline. One licensing officer explained the perceived impact of this policy on the number of applications received during the peak period:

It's almost like a red rag to a bull, like as soon as this cumulative impact came in we thought oh, people will calm down, really think things out, and they were like we've got to have it. It's like telling a child no, you cannot have that apple, all of a sudden they want the apple, they don't want the chocolate. [...] And also, I'll be honest, I wasn't expecting, there's not a lot of things that surprise me in licensing any more, because I've been doing it so long. But I wasn't expecting as soon as you do a cumulative impact in one area, people would just go mental, and it was that they needed it more, I need, so all of a sudden I have all these applications, and I'm just like, you know, and of course a lot of them are rejected and then you end up with appeals (Council, licensing officer).

As part of our continued work we are examining both the issue of how CIPs impact the number and types of applications submitted and the number and types of applications granted within the context of alcohol licencing meetings as well as during the appeal process. Below we describe five interrelated areas where CIPs were contested in licensing meetings.

\section{2(a) Contested Namings}


Examining the everyday world of licencing meetings in London boroughs revealed the differential ways in which the policy under examination was referenced. Licensing documents (e.g., texts in the public documents pack such as the meeting agenda, licensing applications and representations) and statements made orally in licensing committee meetings from different stakeholders, demonstrated marked inconsistency with how the policy was referenced or if it was referenced at all.

For example, in the context of a single licencing subcommittee meeting, people sometimes talked-seemingly interchangeably-about the "cumulative impact policy", "cumulative impacts zones", "cumulative impacts areas", and "special policy areas" that impacted the application under question. In some cases within licencing meetings, the policy was not mentioned explicitly by name but references were made to the "dangers of market saturation" or the "negative effects of cumulation" that the council agreed to address. These "market saturation" and "cumulation" negative effects were referenced in relation to the social harms of alcohol overprovision (e.g., antisocial behaviour) as opposed to the healthrelated harms in the borough. In another example of this tension, during discussion of an offlicence application one councillor exclaimed to an applicant's lawyer: "Wait, what policy or area rule are you talking about? That little acronym, S.I.P. [sic] I think, you keep using doesn't mean anything to me" (Councillor on Licensing Board).

Differential namings appear to create some confusion in the context of licensing meetings and the broader policy literature. For example, it is worth noting that outside of the London borough we have focused on, policies addressing the negative cumulative impact of alcohol outlet density were commonly referenced using other names including the somewhat vague "Special Policy" and "Special Policy Areas" in a neighbouring borough. That said, in some regions a Special Policy Area is not a synonym for a CIP but rather a sub-area within a CIP where more stringent criteria are applied (making application rejections more likely). Adding further complexity, in Scotland-where 'protecting and improving public health' is a fifth licensing objective under their Licencing Act (2005) - similar policies targeting outlet density are in place which are frequently called "overprovision" polices (Scottish Executive 2007).

\section{2(b) Contested Interpretations}

Licensing meetings revealed that the CIP in place was often met with contested interpretations regarding its purpose. For example, different stakeholders frequently described, implicitly or explicitly, varied ideas regarding why this policy was in place. A notable example, is that on many occasions local residents have made representations based on their apparent understanding that no new on or off premise licences can be granted in their neighbourhood because they are in an area deemed to be "saturated". As one man in the public gallery exclaimed after the decision to grant an on-licence to a "food-led" restaurant was announced: "But I thought we were in a cumulative impact zone!". This apparent frustration epitomises the reactions of many residents who have frequently conveyed exasperation regarding the granting of any new or modified alcohol licences in their residential area.

In some cases, the purpose of having a cumulative impact policy was a matter of discussion. For example, on multiple occasions councillors pushed applicants to explain their understanding of what it meant to be applying for a new or modified licence in the context of 
a CIP. For example, the exchange between an applicant and a councillor on the licencing subcommittee highlights how some applicants were called upon to demonstrate their understanding of the purpose CIPs:

Councillor: You say in your [licensing] pack you know you are in a cumulative impact area. Could you explain what that means?

\section{[Applicant has question translated by daughter]}

Applicant's Translator: A zone that is high in selling alcohol and high in, you know, different troubles...

Councillor: You suggest you know what this means - the cumulative impact. But you don't seem entirely clear. Perhaps you can explain why the cumulative impact area is important and what you are doing to mitigate harm.

In this exchange, and similar exchanges in subcommittee meetings, applicants described their perceived adherence to CIPs by listing how they would be "responsible" retailors. Programs that relate to not selling alcohol to minors, not selling to people who are intoxicated, and implementing staff training were frequently highlighted. Again, these understandings of the purpose of CIPs were articulated in relation to the licensing objectives and, as such, did not include a public health rational or interpretation.

\section{2(c) Contested Framings}

A more subtle, albeit important grounds of contestation, concerned how different actors framed the type of establishment that was under discussion. For example, in the context of CIPs, in many cases an applicant (or an applicant's lawyer) framed their establishment in ways that made the business seem important to the community and not the "type of premise" that would potentially violate the licensing objectives. For example, business were discussed as important for "creating jobs" and "investing in the community". A frequent way of framing on-premise locations was talking about them as "food-led" establishments that involved "simply having a glass of wine with food". This way of talking about a business is in stark contrast others who made representations (such as the police or residents) who talked about the same establishment as a "blight on the community", "places to get loaded and stumble on to other locations" and part of the "problem of the night time economy". While great heterogeneity existed regarding the ways in which different on and off premise locations were framed, the point here is to underscore that the same application was framed quite differently in the context of a licensing meeting with different economic, community and ideological interests combatting.

A related framing issue involves how the intentions of an applicant were contested in some instances. For example, in a number of heated cases those making representations, as well as licensing committee members, stated that the application was not made in "good faith". In some circumstances, the differences seemed to be about how "committed" the applicant was to the community and the fulfilling of the licencing objectives and issues of sincerity were raised. Applications were framed as being "rushed" or critiqued for not having had meaningful involvement with key stakeholders during the development and refinement of the application. However, in a number of cases suspicions of applicants trying "manipulate" 
the licensing committee were made. For example, building on the representations made by a group of residents, a councillor on the licensing panel surmised:

I think what the gentleman [resident making representation] may be saying is 'we smell a rat'. Basically, is this a trojan horse?...Are we starring down the barrel of something much bigger?... What can you do to ensure this committee that this is not a trojan horse with you coming back to us in 6 months to modify your licence further now that you have one in this area of cumulative impact?...Are you going to come back and want offsales? Come in a year and open a night club on this location? (Councillor on Licensing Board).

\section{2(d) Contested Applicability}

A further point, which gets into the details of specific CIPs and CIZs, is contestation on the grounds of applicability. For example, in one case it was argued that the CIP should not be applied because representations were being made on the grounds that an additional offlicence would add to the problem of street drinking. Fourteen representations in this case alone were made by residents to this effect, some being emotional and passionate articulations of the problems of street drinking outside of their homes including the psychological stress and pain of this escalating problem. However, the way the CIP policy was worded in this borough focused on the need to restrict alcohol outlets due to problems of crime, violence and the night time economy. In short, problems of street drinking were not identified in the policy. As such, in this case the specific rational for the CIZ was called into question and weighed against the many written and oral representations made.

\section{2(e) Contested Evidence}

Finally, and of particular importance, CIPs often lead to a great deal of contested evidence in licensing meetings. Two distinct albeit related categories of contested evidentiary claims are made in relation to CIPs: (1) evidence related to the negative effects of alcohol outlet density in the area and (2) evidence of adherence to the licencing objectives and the mitigation of harm relating to a particular premise (or application for a premise).

The first concerns evidence related to why an area has been declared a cumulative impact area and why representations have been made with respects to the policy. The extent to which problems can (or need to be) linked to a particular premises or areas in a CIZ was frequently a matter of heated discussion with differential evidentiary claims. While most evidence that was presented in licencing meetings was discussed in relation to the social harms of alcohol in connection with one or more of the four licensing objectives, in some cases related health harms were also noted by licencing officers and police who referenced looking at area-level "health data" (e.g., hospital admissions data were the most frequently noted).

Varied forms of statistical evidence were offered during the course of making representations. For example, the following is a common exemplar of representations made by police, in their written representations: 
We object on the grounds of cumulative impact. [...] within 150 meter radius from this premise we have 18 off licenses [gave specifics of types of premises]. There is a high rate of crime and disorder. Over 2,500 crimes have been reported [reviews time period of crimes]. This is such a challenging area and we are conserved about, respectively, an inexperienced licence holder (excerpt from police representation).

Another frequently invoked form of evidence related to the negative harms associated with alcohol came in the form of personal testimony and narrative accounts from residents in the area. Like other representations, these parties provided written statements to make their objections to a new or modified licence. In some cases these representations explicitly drew on experiences of seeing the "deterioration" of their neighbourhoods due to high outlet density. While some of the representations were made in free form (as letter or email), in other cases, people made use of forms that have been created to allow representations to be made to the application. It is worth noting these texts are organized in ways to have respondents fill in their objections in one or more of four fields related to the licensing objectives. The following is an example of one such representation where the fear of physical personal safety was articulated:

We are already plagued by drunks vomiting outside out door, drinking on our front steps and fighting and yelling outside our building. I am personally afraid if I come home late in the evening of being accosted by them (excerpt from written resident representation).

In some cases these written representations from residents were drawn upon in the context of the licencing meetings. Like other forms of evidence that were presented, those making the representations from the community were instructed to refer to the evidence presented in the package when providing their oral statements:

So what is a cumulative impact area? To be able to understand what we are talking about here you have to live in the area. We are absolutely saturated with alcohol. [...] The problems with alcohol have just gotten worse and worse. [...] The licensing policy of the council is really strong, really clear on cumulative impact. It puts the burden on the people making the application. They have to persuade the council that they will not add to the cumulative impact. I know...I don't think they have done that in their pack. [...] We are concerned this new premise will add to the cumulative impact. It can't have any other effects (excerpt from oral resident representation).

The second area of contested evidence concerns how an applicant can demonstrate adherence to, and promotion of, the licencing objectives and any mitigation of possible harms caused. Supporting evidence tended to relate specifically to the premise/application in question rather than area-level evidence of health and crime. In fact, one section of the lengthy license application package asks applicants to describe how they intend to promote the four licensing objectives individually and collectively. In some cases, this is where other alcohol interventions such as 'Reducing the Strength' (RtS) (a voluntary program for removing high-strength inexpensive beer and cider from off-licences) were referenced as evidence of meeting the licensing objectives and demonstrating "responsibility to the community". In most instances, such evidence was outlined within an application package and did not change during the licensing meeting process. In other cases, however, provisions 
such as RtS were added within the context of the meeting to alleviate concerns raised by councillors and/or those making representations.

For example, this exchange between a councillor and applicant demonstrates the process of evidence demonstration in the context of a licencing meeting:

Councillor (on licensing committee): We are in a cumulative impact zone, you are quite right...I am looking for the evidence that this premise, that this extra availability of alcohol will not lead to harm, not violate our [licensing] objectives...I am not laying all the problems in the area on your doorstep but I am looking for evidence. Where is the mitigation?"

Applicant's Legal Representative: ...This is a small café for a limited number of people. If you turn to page 74 [references appendix in the licencing pack] you will see that my client is responsible [...] has done everything possible to avoid harm and not violate your objectives.

In this case the applicant's legal representative referenced a section in the licencing application which outlined 21 conditions of the licence originally stipulated as well as other voluntary additional conditions made after hearing the concerns of police and the noise team. This area of evidence appears particularly contested in the context of CIPs with varying competing claims about the evidentiary burden required to demonstrate both adherence to the licencing objectives and the mitigation of any harm that may be caused by a new or modified license.

\section{Discussion}

In this study we explored the implementation of CIPs in one Local Government area in London to specifically understand the development and impact of local decision-making processes affecting alcohol availability. Institutional ethnography revealed that at the local level, CIPs were contested on multiple grounds and served to institutionally organize a complex process of work on alcohol licensing. Conflicts of interest arose during the statutory implementation processes that involved text-mediated dialogue between alcohol retailers, local government policymakers, and residents. Much of this work in alcohol licensing between different actors focused on interpreting how text-bounded policy statements (CIPs) apply to particular cases (licensed premise applications) requiring decision. During this process, depictions of the policy goals and aims, the application's merits, and the applicant's intentions and demonstration of "responsibility" were negotiated and framed differentially according to the interests and viewpoints of diverse stakeholders.

Some applicants actively sought to understand how implementers interpreted and operationalized their policy, so that applications could include features considered compatible with CIP goals and exclude potentially contrary elements. Perhaps not surprisingly, applicants that adopted this strategy frequently appeared to be well-resourced and have experience in making licensing applications, for example those representing national retail chains. Further, these applicants avoided the appearance of applying for an outlet that was "alcohol-led" and/or likely to encourage public drunkenness and antisocial behaviour. Successful applicants also frequently used prior contact with implementers and negotiating skills during informal and formal licensing meetings to demonstrate their apparent sincerity and co-operative approach. 
The net result is a process that can be flexible and interpretive but currently appears to favour a certain type of licensed venue (e.g., food, coffee or arts led establishments) and a certain type of vendor (e.g., well resourced, co-operative, skilled at self-presentation) which are perceived as responsible retail practices likely to lead to less crime and are consistent with the aims of the licensing objectives. Hence, the CIP we have studied is geared towards reshaping the local alcohol environment in a much more subtle way than simply limiting alcohol outlet density. The 'premises by premises' approach to judging the potential harms of a license application can at times make evidence based on area-level health statistics appear less relevant, and provides well resourced applicants with an opportunity to argue the case for new licenses even in CIP areas with high outlet density. A recent review of UK licensing has argued that there is, however, significant scope in law to enable licensing authorities to consider interactions between a premise and the local environment when deciding upon an application (Foster, 2016).

As Humphreys and Smith (2013) observe, in the United Kingdom "[d]ebates about how to prevent alcohol-related harm are, at present, predominantly focused on the affordability of alcohol" (110). However, our study reveals how availability-focused policies have led to much greater local debate among diverse stakeholders including retailors, police, licensing, public health, councillors, and local residents. It is worth noting that in some neighbourhoods it appears that residents are particularly well organized and vocal about combatting new applications, primarily objecting on grounds of antisocial behaviour.

Given the existing licencing objectives, discussions related to CIPs and alcohol outlet density within licensing subcommittee meetings predominantly have focused on the social harms of alcohol misuse in public settings rather than health harms for people consuming alcohol, health inequalities, or social harms in home settings. This practice of not explicitly accounting for health evidence when applying the objectives of the Licencing Act at the local level continues despite analysis by the Home Office on the economic and health-related advantages of including health as an objective in the Licensing Act (2003) specifically as related to CIPs (Home Office 2012a).

Our ethnographic research was predicated on the view that a key component of understanding the possible impacts of an intervention involves seeing how it is conceived and delivered in everyday practice. Both the form and function of CIPs were contested at the local level and some actors in CIP processes appeared poorly informed about the policy. Perhaps this is not surprising given the lack of clarity that existed in national guidance concerning CIPs. Recent work by the Home Office has sought to clarify the purpose of CIPs for local authorities and explain how such policies can be crafted and implemented (Home Office, 2015). Further education at the local level to inform both residents and councillors about CIPs would be valuable, particularly if it included clarification of the public health arguments that can be employed to justify the creation of a CIP and influence decisions on specific applications. We argue that further attention to the reasons why local authorities choose to implement CIPs, how local authorities implement CIPs, and the resources required for implementation (including those related to legal appeals being made by large retail chains) is required.

\section{Conclusion}


CIPs can be used to exemplify two related problems facing attempts to prevent and reduce health harms related to alcohol consumption: firstly, the perceived need to restrict alcohol availability locally in the absence of stricter national policies enforcing availability restrictions; and secondly, the need to prioritise health protection within alcohol policy. The ethnographic approach used helped us to understand the everyday, local world of alcohol policy from the standpoint of diverse actors involved in the work of alcohol licencing.

Our study has shown how, even within a single local authority, CIPs represented a fluid rather than a fixed policy in terms of its objectives and framings. This fluidity is often a consequence of the case-by-case nature of the licensing decision-making we observed. The study also showed how multiple stakeholders interpreted CIPs differently and negotiated for outcomes that favoured their own interests. Within that process of negotiation, public health priorities and evidence can variously intersect with, or stand outside the interests of other local authority stakeholders, residents and commercial interests. When considering applications on a case-by-case basis, the licencing process still appeared to focus on social disorder more than health harms. At times this policy strategy also appeared to favour wellresourced stakeholders who had the time, knowledge, and skills to present their own interests as commensurate with the requirements of the CIP.

Despite some challenges to implementation, local decision-makers in the borough we studied have remained committed to implementing CIPs alongside a range of other alcohol related-interventions. Public health goals could be served by continuing to make the case for prioritising health objectives within local alcohol strategies and for granting greater powers to restrict alcohol availability and prioritise health concerns at a national level.

\section{References}

Author A et al. (2013).

Author A et al. (2014).

Author A et al. (2015).

Ayuka, F., Barnett, R., and Pearce, J. (2014). Neighbourhood availability of alcohol outlets and hazardous alcohol consumption in New Zealand. Health and Place 29, 186-99.

Babor, T.F., Caetano, R., Casswell, S., Edwards, G., Giesbrecht, N., Graham, K., Grube, J., Gruenewald, P., Hill, L., Holder, H., Homel, R., Livingston, M., Österberg, E., Rehm, J., Room, R., and Rossow, I. (2010). Alcohol: no ordinary commodity. Research and public policy. Oxford University Press: New York.

Booth, A., Brennan, A., Meier, P.S., O'Reilly, D.T., Purshouse, R., Stockwell, T., Sutton, A., Taylor, K.B., Wilkinson, A., and Wong, R. (2008). Independent review of the effects of Alcohol Pricing and Promotion: Part A: Systematic Reviews Project Report for the Department of Health. Sheffield, ScHARR University of Sheffield.

Campbell, C.A., Hahn, R.A., Elder, R., Brewer, R., Chattopadhyay, S., Fielding, J., Naimi, T.S., Toomey, T., Lawrence, B., Middleton, J.C. (2009). The Effectiveness of Limiting 
Alcohol Outlet Density as a Means of Reducing Excessive Alcohol Consumption and Alcohol-Related Harms. American Journal of Preventive Medicine 37(6), 556-569.

Campbell, M. and Gregor, F. (2002). Mapping Social Relations: A Primer in Doing Institutional Ethnography. Aurora: Garamond Press.

de Vocht, F., Heron, J., Angus, C., Brennan, A., Mooney, J., Lock, K., ... \& Hickman, M. (2016). Measurable effects of local alcohol licensing policies on population health in England. Journal of Epidemiology and Community Health 70:231-237

DeVault, M. and McCoy, L. (2002). Institutional ethnography: Using interviews to investigate ruling relations. In J. F. Gubrium \& J. A. Holstein (Eds.), Handbook of interviewing: Context and method (pp. 751-775). Thousand Oaks, CA: SAGE.

Eastwood, L. E. (2013). The social organization of policy: An institutional ethnography of UN forest deliberations. Routledge.

Foster, J. (2016). The Licensing Act (2003): its uses and abuses 10 years on. Institute of Alcohol Studies.

Gmel, G., Holmes, J., and Studer, J. (2015). Are alcohol outlet densities strongly associated with alcohol-related outcomes? A critical review of recent evidence. Drug and Alcohol Review.

Gruenewald, P.J. and Remer, L. (2006). Changes in outlet densities affect violence rates. Alcoholism: Clinical and Experimental Research 30(7), 1184-93.

Hawkins, K. (2002). Law as last resort: Prosecution decision-making in a regulatory agency. Oxford, UK: Oxford University Press.

Home Office. (2012a). Consultation on including a health objective in the Licensing Act 2003 related specifically to cumulative impact. Impact Assessment.

Home Office. (2012b). The government's alcohol strategy. London: HM Government.

Home Office. (2015). Revised Guidance issued under section 182 of the Licensing Act 2003. London.

Humphreys, D.K. and Smith, D.M. (2013). Alcohol licencing data: Why is it an underused resource in public health? Health \& Place 24, 110-114.

Livingston, M., Chikritzhs, T., and Room, M. (2007). Changing the density of alcohol outlets to reduce alcohol-related problems. Drug and Alcohol Review 26, 553-62.

Martineau, F., Tyner, E., Lorenc, T., Petticrew, M., and Lock, K. (2013). Population-level interventions to reduce alcohol-related harm: an overview of systematic reviews. Preventive medicine 57(4), 278-296.

McCoy, L. (2006). Keeping the institution in view: Working with interview accounts of everyday experience. In D. Smith (Ed.), Institutional ethnography as practice (pp. 109125). Toronto, ON: Rowman \& Littlefield Publishers. 
Morris, J. (2015). Licensing figures 2014: premises down slightly, but reviews still falling and questions over 're-balancing' measures. Alcohol Policy UK.

Mykhalovskiy, E., and McCoy, L. (2002). Troubling ruling discourses of health: Using institutional ethnography in community-based research. Critical Public Health, 12(1), 17-37.

Nicholls, J. (2012). The Government Alcohol Strategy 2012: Alcohol policy at a turning point? Drugs: Education, Prevention, and Policy 19(5), 355-359.Ollila, E. (2011). Health in all policies: from rhetoric to action. Scandinavian Journal of Public Health, 39(6 suppl), 11-18.

Popova, S., Giesbrecht, N., Bekmuradov, D., and Patra, J. (2009). Hours and days of sale and density of alcohol outlets: impacts on alcohol consumption and damage: a systematic review. Alcohol \& Alcoholism 44(5), 500-16.

Rankin, J. M. (2003). 'Patient satisfaction': knowledge for ruling hospital reform-An institutional ethnography. Nursing Inquiry, 10(1), 57-65.

Scottish Executive. (2007). Licensing (Scotland) Act 2005-Section 142-guidance for licensing boards. Edinburgh: Scottish Executive.

Stockwell, T. and Gruenewald, P.J. (2004). Controls on the physical availability of alcohol. The Essential Handbook of Treatment and Prevention of Alcohol Problems. N. Heather and T. Stockwell. New York, John Wiley \& Sons, Ltd.: 213-233.

Smith, D. (1987). The everyday world as problematic: A feminist sociology. Boston, MA: Northeastern University Press.

Smith, D. (1990). Texts, facts, and femininity: Exploring the relations of ruling. London, United Kingdom: Routledge.

Smith, D. (1999). Writing the social: Theory, critique, investigations. Toronto, ON: University of Toronto Press.

Smith, D. (2004). Writing the social: Critique, theory, and investigations. Toronto, ON: University of Toronto Press.

Smith, D. (2005). Institutional ethnography: A sociology for people. Lanham, MD: Altamira.

Smith, D. (2006). Institutional ethnography as practice. New York, NY: Rowman \& Littlefield Publishers.

Woodhouse, J. (2015). Alcohol: Cumulative Impact Policies. Briefing Paper. www.parliament.uk/commons-library | intranet.parliament.uk/commons-library.

World Health Organization. (2010). Adelaide statement on health in all policies: Moving towards a shared governance for health and well-being. Government of South Australia, Adelaide. 


\footnotetext{
${ }^{\mathrm{i}}$ In England, there are a total of 326 (LTLAs) or districts: 32 London boroughs, 36 metropolitan districts, 201 non-metropolitan districts, 55 unitary authorities, as well as the City of London and Isles of Scilly. As of 2014, there were 209 CIPs being implemented by 103 LTLAs (Morris 2015).
} 